\title{
Hemodynamic Responses and intubating conditions in laryngeal mask airway insertion a comparative study of propofol versus sevoflurane
}

\author{
Mathew $\mathbf{S}^{1}$, Peter $\mathbf{V}^{2}$, Thomas M. $\mathbf{K}^{3}$ \\ ${ }^{1}$ Dr. Sumesh Mathew, Assistant Professor, ${ }^{2}$ Dr. Vijil Peter, Assistant Professor, ${ }^{3}$ Dr. Mariam Koshy Thomas, Professor \& \\ Head, all authors are affiliated with Department of Anaesthesiology, Jubilee Mission Medical College and Research \\ Institute, Thrissur, Kerala, India.
}

Address for Correspondence: Dr. Sumesh Mathew, Mundiyanickal house, Thellakom P O, Kottayam, Kerala, India. Email: sumesh.math@gmail.com

\begin{abstract}
Background: LMA is an effective alternative to the endotracheal tube for securing the airway in short surgical procedures. Propofol is a widely used anaesthetic agent for the insertion of Laryngeal Mask Airway. Sevoflurane is a volatile anaesthetic agent, which combines rapid, smooth inhalational induction of anaesthesia with rapid recovery, making it ideal for day care anaesthesia. Objective: To study if the use of sevoflurane can be used as an alternative to IV propofol for laryngeal mask airway insertion. Primary objective: Hemodynamic responses during Laryngeal mask insertion. Secondary objective: Intubating conditions during laryngeal mask airway insertion. Study design: A Randomized control trial. Methods: 100 adults were allocated by randomization into two groups of 50 each; group P (Propofol) and group S (Sevoflurane). Patients in group P were induced with $2.5 \mathrm{mg} / \mathrm{kg}$ intravenous propofol with $50 \%$ $\mathrm{O}_{2} \& 50 \% \mathrm{~N}_{2} \mathrm{O}$ and in group $\mathrm{S}$ with $8 \%$ sevoflurane in $50 \% \mathrm{O}_{2} \& 50 \% \mathrm{~N}_{2} \mathrm{O}$ vital capacity breath technique. Laryngeal mask airway was inserted after adequate jaw relaxation was attained and hemodynamic responses like pulse rate, blood pressure were monitored. The grading of conditions for laryngeal mask airway insertion and number of attempts were noted. All the data collected was analysed statistically. Results: We observed that more number of attempts were required for LMA insertion in Group S (14.0\%) compared to Group P $(0.0 \%)$ which is statistically significant with $\mathrm{P}=0.012$. Heart rate at one minute and 2 minutes after LMA insertion showed a fall with Propofol which was statistically significant as compared to Sevoflurane. There is a significant difference of fall in mean arterial blood pressure in group P during induction, one minute, 2 minutes and 5 minutes when compared between the two groups. Sevoflurane took longer time for induction and LMA insertion compared to Propofol which is statistically significant. Moderate patient movement were noticed in 5 patients of group $\mathrm{S}$ and no patient movement were noticed in group $\mathrm{P}$ and is statistically significant $(\mathrm{P}-\mathrm{0.022})$. Quality of insertion with propofol was excellent in all patients. With sevoflurane quality of insertion ranged from excellent to satisfactory. Conclusion: Sevoflurane is associated with good hemodynamic stability but intubating conditions provided with propofol is superior. Prolonged time for jaw relaxation with sevoflurane when compared to propofol may delay laryngeal mask airway insertion. Quality of insertion with propofol was excellent in all patients. With sevoflurane quality of insertion ranged from excellent to satisfactory.
\end{abstract}

Keywords: Laryngeal Mask Airway, Propofol, Sevoflurane

\section{Introduction}

Laryngeal mask airway has been used in millions of patients and is accepted as a safe technique, in variety of surgical procedures [1]. It ensures a better control of airway than the facemask, leaving the anesthetists hands

Manuscript received: $7^{\text {th }}$ March 2017

Reviewed: $16^{\text {th }}$ March 2017

Author Corrected: $24^{\text {th }}$ March 2017

Accepted for Publication: $31^{\mathrm{st}}$ March 2017 free and avoids the disadvantages of endotracheal tube like presser response during intubation and sore throat, croup, hoarseness postoperatively. Laryngeal mask also provides an effective and simple solution to many problems of difficult intubation. The laryngeal mask airway is an ingenious supraglottic airway device that is designed to provide and maintain a seal around the 
laryngeal inlet for spontaneous ventilation and allow controlled ventilation at modest levels $(<15 \mathrm{cms}$ of $\mathrm{H} 2 \mathrm{O}$ ) of positive pressure [2]. With use of LMA, muscle relaxation is unnecessary, laryngoscopy is avoided and hemodymanic changes are minimized during insertion [2]. Ideal induction agent for LMA insertion would provide loss of consciousness, jaw relaxation, absence of upper airway reflexes rapidly without cardio respiratory compromise. Most currently available induction agents have been used for LMA insertion, but propofol is probably the best intravenous agent and sevoflurane is the best volatile agent, though neither is ideal [1].

IV propofol with or without opioid is the induction agent of choice for laryngeal mask airway insertion. Because of its favourable recovery profile and low incidence of side effects, propofol has become the drug of choice for insertion of laryngeal mask airway, but is associated with pain on injection and cardiovascular and respiratory depression [3]. Sevoflurane, a halogenated, volatile anesthetic agent is nonirritating to the airways, and mask induction with this agent is associated with a very low incidence of breath holding, coughing, and laryngospasm. In addition, low lipid solubility allows a fast, smooth induction; and a predictably short recovery. Induction technique using a high inspired concentration of sevoflurane and vital capacity breaths provides good conditions for the insertion of LMA [4]. Recently, vital capacity breath inhaled induction of anesthesia with sevoflurane has been used as an alternative to intravenous induction in adults.

This method is rapid, with little excitatory phenomena, high patient acceptance and good hemodynamic stability [5]. Rapid insertion of LMA after vital capacity breath induction may allow the use of sevoflurane as a single drug for the induction and maintenance of anesthesia, which would ease the transition period and lead to cost saving [6].

Aims of the study is

- To compare the induction with sevoflurane and propofol for LMA insertion.

- To assess the quality of jaw relaxation between them for LMA insertion.

- To estimate the incidence of respiratory complications (laryngospasm, coughing, and gagging) and cardio vascular complications with both agents.

\section{Materials and Methods}

A prospective randomized study was conducted on 50 ASA grade I \&II patients, aged between 18 - 60 years who are undergoing minor surgical procedures under general anesthesia. Both inpatients and day cases were included in the study. They were randomized into two groups of 25 each.

Group S - sevoflurane group

Group $\mathrm{P}$ - propofol group

\section{Inclusion criteria}

Patients of age between $18-60$ years

ASA grade I \& II patients

\section{Exclusion criteria}

Adults <18years, >60years

ASA III, IV, V

Morbidly obese

Patients requiring endotracheal intubation, A preanesthetic evaluation was done on the previous day of surgery and was reviewed on the day of surgery. A detailed medical history was taken. Systemic examination was arried out and relevant investigations were advised. An informed written consent was taken from all patients. Nil per oral status was maintained for all patients.

Patients were premeditated with tab. Ranitidine $150 \mathrm{mg}$ and tab Ondansetron 4mg. On arrival to operation room- IV line was secured, Monitors for ECG, NIBP and SPO2 were connected. Patients received injection fentanyl $1.5-2 \mu \mathrm{g} / \mathrm{kg}$ prior to induction. All patients were preoxygenated for $3 \mathrm{~min}$ with $100 \%$ oxygen using a fresh gas flow of $81 / \mathrm{min}$. Patients were randomly allocated into group $\mathrm{S}$ and group P. Patients baseline vital data like heart rate, NIBP, SPO2 was recorded.

Group P - received propofol $2-2.5 \mathrm{mg} / \mathrm{kg}$ body weight at the rate of $40 \mathrm{mg}$ every $10 \mathrm{sec}$ was given.

Group S - Sevoflurane 8\% was introduced into fresh gas flow of 81 of oxygen and patients were instructed to take vital capacity breath and hold it as long as they could. The point of start of injection of propofol or introduction of sevoflurane $8 \%$ was considered as starting point of induction. Their anesthesia circuit was primed with $8 \%$ sevoflurane with $\mathrm{O} 2$ at $8 \mathrm{~L} / \mathrm{min}$. 
Loss of verbal contact was considered as the desired endpoint for induction in both techniques which was assessed by the response to calling out the patient's name. Then the time of loss of eyelash reflex was noted. After this jaw relaxation was assessed by anesthesiologist after loss of eyelash reflex, If jaw relaxation was not adequate, it was reassessed after every 15 seconds. Once jaw relaxation was adequate, LMA insertion was attempted. The following data was recorded.

1. Time taken from start of induction to loss of verbal contact, loss of eyelash reflex, jaw relaxation and successful LMA insertion.

2. Number of attempts of LMA insertion.

3. Total dose of requirement of propofol in each patients.

4. NIBP, HR and SPO2 were monitored from beginning of induction up to 5 minutes of induction.

The conditions of insertion of LMA were graded by observer on a three point scale using 6 variables based on LMA insertion score [3, 8]. Overall conditions for insertion of LMA were assessed as excellent, satisfactory or poor on basis of total score obtained by summing up the individual scores of each component. [Maximum score of 18].

The following parameters are assessed during LMA insertion: Jaw relaxation, Ease of LMA insertion, Coughing, Gagging, Laryngospasm, Number of attempts of LMA insertion.

Excellent 18, Satisfactory $16-17$ and Poor $<16$.
LMA was inserted by the method described by Brain. After insertion of LMA, anaesthesia was continued with $66 \% \mathrm{~N} 2 \mathrm{O}+33 \% \mathrm{O} 2+$ isoflurane. The study ended when the patient was considered to reach an adequate depth of anaesthesia and was well settled after insertion of LMA. Manual ventilation was employed if necessary. Study design: This is a randomised control trial. All eligible consenting persons will be included in the study and randomly allocated on the basis of a randomisation list in the study arm.

Statistical Methods: Descriptive statistical analysis has been carried out in the present study. Results on continuous measurements are presented on Mean $\pm S D$ (Min-Max) and results on categorical measurements are presented in Number (\%). Significance is assessed at $5 \%$ level of significance. The following assumptions on data is made, Assumptions: 1.Dependent variables should be normally distributed, 2.Samples drawn from the population should be random, Cases of the samples should be independent.

Student t test (two tailed, independent) has been used to find the significance of study parameters on continuous scale between two groups (Inter group analysis) on metric parameters. Levene's test for homogeneity of variance has been performed to assess the homogeneity of variance. Chi-squarel Fisher Exact test has been used to find the significance of study parameters on categorical scale between two or more groups.

Significant figures used are statistically not significant $P$ value: $>0.05$

Statistically significant - P value: $\leq 0.05$, Strongly significant - $\mathrm{P}$ value : $\mathrm{P} \leq 0.01$

\section{Results}

A Comparative two arm clinical study with 100 patients randomized in to two groups, 50 patients in Group P (Propofol) and 50 patients in Group S (sevoflurane) is undertaken to study the Haemodynamic responses and intubating conditions during laryngeal mask airway insertion.

There is no statistically significant difference in age distribution. Samples are age matched with $[\mathrm{P}=0.610]$. There is no statistically significant difference in weight distribution. Samples are weight matched with [ $\mathrm{P}=0.719]$.

In group P $88 \%$ of patients were in ASA grade 1 and $12 \%$ were in ASA grade 2. In group S $80 \%$ of patients were in ASA grade 1 and $20 \%$ were in ASA grade 2.

In group P 46 patients were used LMA size 3 and 4 were used LMA size 4 for their surgical procedure. In group S 48 patients were used LMA size 3 and 2 were used LMA size 4 for their surgical procedure. 
Table-I: Number of attempts.

\begin{tabular}{|c|c|c|c|c|}
\hline \multirow{2}{*}{ No of attempts } & \multicolumn{2}{|c|}{ Group I } & \multicolumn{2}{c|}{ Group II } \\
\cline { 2 - 5 } & No & $\%$ & No & \% \\
\hline 1 attempt & 50 & 100.0 & 43 & 14.0 \\
\hline 2 attempts & 0 & 0.0 & 50 & 100.0 \\
\hline Total & 50 & 100.0 & 7 & \\
\hline
\end{tabular}

Inference: All patients of group P (propofol) in this study had successful LMA insertion in $1^{\text {st }}$ attempt. 43 patients of group $S$ (sevoflurane) had successful LMA insertion in $1^{\text {st }}$ attempt and 7 patients were undergone 2nd attempt for successful LMA insertion. The number of attempts are more in Group S (14.0\%) compared to Group P $(0.0 \%)$ which is statistically significant with $[\mathrm{P}=0.012]$.

Table-II: Comparison of Pulse rate in two groups of patients studied.

\begin{tabular}{|c|c|c|c|}
\hline Pulse & Group I & Group II & P value \\
\hline Base line & $84.00 \pm 8.13$ & $85.00 \pm 7.53$ & 0.525 \\
\hline Induction & $81.48 \pm 7.84$ & $84.48 \pm 8.11$ & 0.063 \\
\hline 1 minute & $78.48 \pm 8.49$ & $86.48 \pm 10.63$ & 0.004 \\
\hline 2 minutes & $77.04 \pm 9.08$ & $83.08 \pm 11.21$ & 0.086 \\
\hline 5 minutes & $76.40 \pm 9.95$ & $79.84 \pm 9.87$ & 0.01 \\
\hline
\end{tabular}

Inference: Comparison of heart rate between the two groups was done using student t test. The heart rate at baseline and at the time of induction were comparable between the groups. Heart rate at one minute and 2 minutes after LMA insertion showed a fall in heart rate with propofol compared to Sevfurane which is statistically significant as compared to the sevoflurane group.No statistically significant difference was noted at 5 minutes after induction.

Table- III: Comparison of Blood pressure (SBP mmHg) in two groups of patients studied.

\begin{tabular}{|c|c|c|c|}
\hline SBP mmHg & Group I & Group II & P value \\
\hline Base line & $124.88 \pm 8.62$ & $125.48 \pm 5.78$ & 0.684 \\
\hline Induction & $120.24 \pm 9.58$ & $125.75 \pm 11.16$ & 0.009 \\
\hline 1 minute & $110.70 \pm 9.03$ & $117.80 \pm 10.65$ & $<0.001$ \\
\hline 2 minutes & $105.60 \pm 8.12$ & $112.32 \pm 8.69$ & 0.188 \\
\hline 5 minutes & $101.32 \pm 9.51$ & $104.04 \pm 10.84$ & \\
\hline
\end{tabular}

Inference: There was no statistically significant difference in systolic blood pressure in baseline between the two groups. There is statistically significant difference in systolic blood pressure at induction, one minute and two minute when compared between the two groups. A fall in the systolic blood pressure in group $\mathrm{P}$ was noted when compared to group S. There is no statistically difference fall in blood pressure between the two groups at 5 minutes.

Table IV: Comparison of Blood pressure (DBP mmHg) in two groups of patients studied.

\begin{tabular}{|c|c|c|c|}
\hline DBP mmHg & Group I & Group II & P value \\
\hline Base line & $78.64 \pm 6.55$ & $80.24 \pm 7.21$ & 0.252 \\
\hline Induction & $76.56 \pm 6.60$ & $80.48 \pm 8.72$ & $<013$ \\
\hline 1 minute & $69.36 \pm 4.90$ & $74.00 \pm 7.55$ & 0.004 \\
\hline 2 minutes & $68.16 \pm 5.23$ & $71.92 \pm 7.39$ & 0.004 \\
\hline 5 minutes & $64.24 \pm 9.32$ & $69.20 \pm 7.51$ & \\
\hline
\end{tabular}


Inference: There was no statistically significant difference in diastolic blood pressure in preoperative period between the two groups. There was statistically significant difference in diastolic blood pressure at induction, one minute, 2 minute and 5 minutes when compared between the two groups. A fall in the diatolic blood pressure in group P was noted when compared to group $\mathrm{S}$ at induction, 1,2 and 5 minute.

Table- V: Comparison of Blood pressure (MAP mmHg) in two groups of patients studied.

\begin{tabular}{|c|c|c|c|}
\hline MAP mmHg & Group I & Group II & P value \\
\hline Base line & $93.80 \pm 6.81$ & $95.88 \pm 6.07$ & 0.125 \\
\hline Induction & $91.04 \pm 6.32$ & $95.20 \pm 8.13$ & 0.005 \\
\hline 1 minute & $82.92 \pm 5.15$ & $88.72 \pm 7.18$ & $<0.001$ \\
\hline 2 minutes & $80.52 \pm 5.25$ & $85.80 \pm 6.92$ & $<0.001$ \\
\hline 5 minutes & $76.48 \pm 8.04$ & $81.00 \pm 6.58$ & 0.003 \\
\hline
\end{tabular}

Inference: There was no statistically significant difference in mean arterial blood pressure in preoperative period between the two groups. There was significant difference in mean arterial blood pressure during induction, one minute, 2 minutes and 5 minutes when compared between the two groups. A fall in the mean blood pressure in group $\mathrm{P}$ was noted when compared to group S.

Table-VI: Time of events.

\begin{tabular}{|c|c|c|c|}
\hline & Group I & Group II & P value \\
\hline Loss of verbal contact & $51.40 \pm 9.95$ & $65.40 \pm 9.57$ & $<0.001$ \\
\hline Time of jaw relaxation & $77.40 \pm 8.93$ & $106.00 \pm 13.17$ & $<0.001$ \\
\hline Time of LMA insertion & $88.40 \pm 7.91$ & $126.20 \pm 15.37$ & $<0.001$ \\
\hline
\end{tabular}

Inference: Sevoflurane took longer time for induction and LMA insertion. Loss of verbal contact, adequate jaw relaxation and LMA insertion were earlier with propofol when compared with sevoflurane and is statistically significant.

Table-VII: Grading of conditions for laryngeal mask airway insertion.

\begin{tabular}{|c|c|c|c|c|}
\hline Parameter & Grading & Description & Group p & Group s \\
\hline \multirow[t]{3}{*}{ Jaw opening } & 3 & Full & 50 & 47 \\
\hline & 2 & Partial & 0 & 3 \\
\hline & 1 & Nil & 0 & 0 \\
\hline \multirow[t]{3}{*}{ Ease of insertion } & 3 & Easy & 50 & 50 \\
\hline & 2 & Difficult & 0 & 0 \\
\hline & 1 & Impossible & 0 & 0 \\
\hline \multirow[t]{3}{*}{ Coughing } & 3 & Nil & 50 & 50 \\
\hline & 2 & Minor & 0 & 0 \\
\hline & 1 & Severe & 0 & 0 \\
\hline \multirow[t]{3}{*}{ Gagging } & 3 & Nil & 50 & 50 \\
\hline & 2 & Minor & 0 & 0 \\
\hline & 1 & Severe & 0 & 0 \\
\hline \multirow[t]{3}{*}{ Laryngospasm } & 3 & Nil & 50 & 50 \\
\hline & 2 & Partial & 0 & 0 \\
\hline & 1 & Total & 0 & 0 \\
\hline \multirow[t]{3}{*}{ Patient movements } & 3 & Nil & 50 & 45 \\
\hline & 2 & Moderate & 0 & 5 \\
\hline & 1 & Vigorous & 0 & 0 \\
\hline
\end{tabular}


Table-VII: Grading.

\begin{tabular}{|c|c|c|c|}
\hline & Group I & Group II & P value \\
\hline Jaw opening & $3.00 \pm 0.00$ & $2.94 \pm 0.23$ & 0.080 \\
\hline Ease of insertion & $3.00 \pm 0.00$ & $3.00 \pm 0.00$ & - \\
\hline Coughing & $3.00 \pm 0.00$ & $3.00 \pm 0.00$ & - \\
\hline Gagging & $3.00 \pm 0.00$ & $3.00 \pm 0.00$ & - \\
\hline Laryngospasm & $3.00 \pm 0.00$ & $3.00 \pm 0.00$ & 0.022 \\
\hline Patient movements & $3.00 \pm 0.00$ & $2.90 \pm 0.31$ & - \\
\hline
\end{tabular}

Inference: Occurrence of complications likes coughing, biting, and laryngospasm during LMA insertion were not noticed in both the groups of this study. The overall insertion was excellent with propofol with all 50 patients scoring 18 . With sevoflurane, 43 patients had excellent conditions for LMA insertion and 7 had satisfactory condition for LMA insertion when grading was done using 18 point score. Jaw opening was partial in 3 patients in group $\mathrm{S}$ but there is no statistically significant difference $(\mathrm{P}-0.080)$ between the groups. Moderate patient movement were noticed in 5 patients of group $\mathrm{S}$ and no patient movement were noticed in group $\mathrm{p}$ and is statistically significant $(\mathrm{p}-0.022)$.

\section{Discussion}

Hemodynamic changes while inserting LMA- Heart rate at 1 minute and 2 minutes after LMA insertion showed a fall in propofol group as compared to sevoflurane group which was statistically significant with [p value of $<0.001$ and 0.004 ] respectively. There was no statistically significant difference in systolic blood pressure in preoperative period between the two groups. A significant fall in the systolic blood pressure in-group $\mathrm{P}$ was noted when compared to group $\mathrm{S}$ at induction, one and two minutes. There was statistically significant fall in diastolic blood pressure at induction, one minute, 2 minute and 5 minutes when compared between the two groups. There was significant fall in mean arterial blood pressure during induction, one minute, 2 minutes and 5 minutes when compared between the two groups.

A Thwaites, S Edmends and I Smith [6] while comparing the hemodynamic parameters noted induction of anaesthesia with propofol was associated with decrease of approximately $20 \mathrm{mmHg}$ in MAP which occurred within $2 \mathrm{~min}$ and persisted for at least 5 min of anaesthesia. In contrast they noted that decrease with MAP with sevoflurane was only $10 \mathrm{~mm} \mathrm{Hg}$. The MAP was significantly lower at 2- 5 minutes after induction with propofol compared with sevoflurane. Heart rate did not differ significantly between the groups at any time during the induction. In our study there is significant difference in mean arterial blood pressure during induction, one minute, 2 minutes and 5 minutes which is comparable in both studies. In our study heart rate showed a significant difference between the groups at one and two minutes after LMA insertion Lian et al [5]conducted a study in which found that propofol produced a larger decrease in mean blood pressure compared with sevoflurane and was statistically significant at 4 and 5 minutes after induction. Heart rate were comparable in both groups. But in our study there is significant difference in mean arterial blood pressure during induction, one minute, 2 minutes and 5 minutes and heart rate showed a significant difference between the groups at one and two minutes after LMA insertion.

Charles E. Smith et al[7] found heart rate was lower 5 and 10 minutes after LMA insertion in the sevoflurane$\mathrm{N}_{2} \mathrm{O}$ group versus the control group ( $\mathrm{p}<0.05$ ). But in our study heart rate at 1 minute and 2 minutes after LMA insertion showed a fall in propofol group as compared to sevoflurane group.

Priya et al [8]in their study found that haemodynamic parameters (Mean Arterial Pressure, Heart Rate) between the two groups showed a statistically significant difference in the Mean Arterial Pressure in group $\mathrm{P}$ three minutes after induction but heart rates were comparable in both groups.

However in our study Heart rate at 1 minute and 2 minutes after LMA insertion showed a fall in propofol group as compared to sevoflurane group and a significant fall in mean arterial blood pressure during induction, one minute, 2 minutes and 5 minutes when compared between the two groups. 
Timing of insertion of LMA insertion-In our study mean time taken from induction to successful laryngeal mask insertion was significantly shorter with propofol compared with sevoflurane. With sevoflurane group the LMA insertion took $126.20 \pm 15.37$ seconds while propofol group took $88.40 \pm 7.91$ seconds with [p< $0.001]$ which is highly significant.

A Thwaites, S Edmends and Smith [6] in their study observed that induction with sevoflurane was significantly slower when compared with propofol, but was associated with lower incidence of apnoea and shorter time to establish spontaneous ventilation.

Lian et al [5] in their study achieved insertion of LMA with sevoflurane in $127 \mathrm{sec}$ almost similar to the time taken in our study (126 sec). They concluded that prolonged jaw tightness after sevoflurane induction of anaesthesia may delay LMA insertion.

Charles E. Smith et al [7] found that time to loss of consciousness was faster after propofol (mean \pm SEM: $51 \pm 3 \mathrm{sec})$ than after sevoflurane- $\mathrm{N}_{2} \mathrm{O}(85 \pm 10 \mathrm{sec} ; p<$ $0.05)$. These findings are comparable to our study.

In contrast Ravikumar Koppula and Anitha Shenoy [3] in their study noted that verbal contact and eyelash reflex with sevoflurane was lost earlier when compared to propofol. But propofol and sevoflurane took similar times to jaw relaxation and subsequent LMA insertion.

\begin{abstract}
Analysis of condition for LMA insertion and patients response- Occurrence of complications likes coughing, biting and laryngospasm during LMA insertion were not noticed in both the groups of this study. The overall insertion was excellent with propofol with all 50 patients scoring 18 . With sevoflurane, 43 patients had excellent conditions for LMA insertion and 7 had satisfactory condition for LMA insertion when grading was done using 18 point score. Jaw opening was partial in 3 patients in group $\mathrm{S}$ but there was no statistically significant difference $(\mathrm{P}-0.080)$ between the groups. Moderate patient movement were noticed in 5 patients of group $\mathrm{S}$ and no patient movement were noticed in group $\mathrm{P}$ and is statistically significant $(\mathrm{p}-0.022)$.
\end{abstract}

Number of attempts for LMA insertion are significantly more in Group S (14.0\%) compared to Group I (0.0\%) with[ $\mathrm{P}=0.012]$. The overall conditions of LMA insertion were graded as excellent in all 50 patients belonging to propofol group. 43 patients in sevoflurane group had excellent conditions with score of 18.6 patients in sevoflurane group had score of 17 and one patient had score of 16 with LMA insertion graded as satisfactory.

Lian et al [5]in their study found that more attempts at insertion of LMA were required in patients in sevoflurane group versus those in propofol group and they suggested that this was primarily because of incidence of initially impossible mouth opening.

In a similar study conducted by Priya et al [8], 4 patients in each group (Group P: Propofol and Group S: Sevoflurane) required a second attempt for insertion of Laryngeal Mask Airway. In the remaining 21 patients each in both groups, Laryngeal Mask Airway was placed successfully at the first attempt itself. Conditions for Laryngeal Mask Airway insertion were noted. Excellent conditions were obtained in a significantly greater number of patients in Group $\mathrm{P}(\mathrm{p}=0.02)$. Analysis of the total scores for conditions for Laryngeal Mask Airway insertion indicated that conditions for Laryngeal Mask Airway insertion were superior in Group P. The mean score in Group P was $17.5 \pm 0.77$ and $16.8 \pm 1.15$ in Group $S(p=0.012)$.

Analysis of the individual scores for criteria for Laryngeal Mask Airway insertion and the patient's response indicated that scores for jaw opening in Group $P$ were significantly better than Group $S$ ( $p=0.047)$. In our study number of attempts were significantly more with sevoflurane compared to propofol and individual scores for criteria for Laryngeal Mask Airway insertion and the patient's response indicated that scores for patient movement in Group $\mathrm{P}$ were significantly better than Group S.

Ganatra SB et al [9] in their study sixty patients were equally and randomly divided into two groups. Both groups received fentanyl $1 \mathrm{microg} / \mathrm{kg}$. Patients in the sevoflurane group were induced with $8 \%$ sevoflurane and those in the propofol group with propofol 2.5 $\mathrm{mg} / \mathrm{kg}$. Excellent or satisfactory conditions were observed in $30(100 \%)$ patients in the propofol group and in $29(96.66 \%)$ in the sevoflurane group.

Ravikumar Koppula and Anitha Shenoy [3] in their study found that both sevoflurane and propofol had similar quality for insertion of LMA and concluded that sevoflurane is a good alternative to propofol for LMA insertion. 


\section{Conclusion}

- In our study sevoflurane is associated with good hemodynamic stability compared to propofol.

- Intubating conditions provided with propofol is superior. Prolonged time for jaw relaxation with sevoflurane when compared to propofol may delay laryngeal mask airway insertion.

- Numbers of attempts for LMA insertion were significantly more with sevoflurane group.

- Quality of insertion with propofol was excellent in all patients. With sevoflurane quality of insertion ranged from excellent to satisfactory.

- Patients who received propofol complained of pain while injection and patients who received sevoflurane complained of odour when the mask was held.

- Sevoflurane is an acceptable alternative to propofol for LMA insertion

\section{Funding: Nil, Conflict of interest: None \\ Permission of IRB: Yes}

\section{References}

1. Robert G Krohner, Sivam Ramanathan. Anatomy of airway in Benumofs airway management 2 nd edition. 2006; 1 - 19, 476 - 497, 1027 - 29.

2. Bogetz MS. Using the laryngeal mask airway to manage the difficult airway. Anesthesiol Clin North America. 2002 Dec;20(4):863-70, vii.
3. Koppula R, Shenoy A. Comparison of sevoflurane with Propofol for LMA insertion. Journal of Anaesthesiology and Clinical Pharmacology, 2005, 21(3), 271-274.

4. Molloy ME, Buggy DJ, Scanlon P. Propofol or sevoflurane for laryngeal mask airway insertion. Can J Anaesth. 1999 Apr;46(4):322-6.

5. Ti LK, Chow MY, Lee TL. Comparison of sevoflurane with propofol for laryngeal mask airway insertion in adults. Anesth Analg. 1999 Apr; 88(4): 908-12.

6. Thwaites A, Edmends S, Smith I. Inhalation induction with sevoflurane: a double-blind comparison with propofol. Br J Anaesth. 1997 Apr;78(4):356-61.

7. Smith, C. E., Lever, J. S., Sawkar, S., Pinchak, A. C., \& Hagen, J. F. Sevoflurane-N2O versus propofol/ isoflurane - $\mathrm{N} 2 \mathrm{O}$ during elective surgery using the laryngeal mask airway in adults. Journal of Clinical Anesthesia 2000, 12(5), 392-396.

8. V Priya, Divatia JV, Dasgupta D. A comparison of Propofol versus sevoflurane for laryngeal mask airway insertion. Indian Journal of Anaesthesia, 2002, 46(1), 31-34.

9. Ganatra SB, D'Mello J, Butani M, Jhamnani P. Conditions for insertion of the laryngeal mask airway, comparisons between sevoflurane and Propofol using fentanyl as a co-induction agent. A pilot study. European Journal of Anaesthesiology,19,2002,371-375.

\section{How to cite this article?}

Mathew S, Peter V, Thomas M. K. Hemodynamic Responses and intubating conditions in laryngeal mask airway insertion a comparative study of propofol versus sevoflurane. Int J Med Res Rev 2017;5(03):253-260 doi:10.17511/ijmrr. 2017.i03.07. 